\title{
The investigation of alumina nanoparticles' effects on the mechanical and thermal properties of HDPE/rPET/MAPE blends
}

\author{
Hamzeh Shahrajabian $^{1}$ (D) $\cdot$ Farzad Sadeghian $^{1}$
}

Received: 2 December 2018 / Accepted: 11 April 2019 / Published online: 20 April 2019

(c) The Author(s) 2019

\begin{abstract}
In this research, the mechanical and thermal properties of nanocomposites containing alumina nanoparticles in the highdensity polyethylene/recycled polyethylene terephthalate/maleic anhydride polyethylene (HDPE/rPET/MAPE) matrix were investigated. For this purpose, tensile, flexural, impact energy, and differential scanning calorimetry (DSC) test were done. Here, $0,1,3$, and $5 \mathrm{wt} \%$ alumina nanoparticles were added to the HDPE/rPET/MAPE using a co-rotating screw extruder. Morphological studies using scanning electron microscopy revealed that alumina nanoparticles within HDPE/rPET/MAPE matrix were well dispersed in low content of nanoparticles (up to $3 \mathrm{wt} \%$ ). The results of mechanical tests showed that the presence of alumina nanoparticles improved tensile strength, elastic modulus, flexural strength, and impact energy. The maximum improvement was observed for the sample containing $3 \mathrm{wt} \%$ of alumina. DSC test revealed alumina nanoparticles in the content of $3 \mathrm{wt} \%$ increased the crystallinity degree of HDPE in the blend of HDPE/rPET/MAPE and caused to approach the melting points of HDPE and rPET.
\end{abstract}

Keywords Recycled polyethylene terephthalate $\cdot$ High-density polyethylene $\cdot$ Maleic anhydride polyethylene $\cdot$ Alumina nanoparticles $\cdot$ Mechanical and thermal properties

\section{Introduction}

Polyethylene terephthalate (PET) is one of the most important types of thermoplastic polymers which is used in the packing and textile industries extensively [1]. Among the most important applications of PET is the production of drink bottle especially water and beverage bottles [2]. Yearly, a lot of bottles are released in the environment, and due to high decomposition time of PET, the accumulation of bottles causes environmental pollution [3]. Therefore, recycling the PET is necessary. Two major techniques of recycling the PET include mechanical and chemical recycling $[4,5]$. Chemical recycling is costly, and therefore, physical recycling is used in recycling the PET extensively. In mechanical recycling, the bottles are melted by the extruder after washing and milling, and the granules of recycled PET (rPET) are prepared. The main disadvantage of physical recycling is that the prepared $\mathrm{rPET}$ is very brittle. To

Hamzeh Shahrajabian

h.shahrajabian@pmc.iaun.ac.ir

1 Department of Mechanical Engineering, Najafabad Branch, Islamic Azad University, Najafabad, Iran overcome this disadvantage, rPET is mixed with other polymers such as polyolefins (polyethylene and polypropylene) [6, 7], EPDM [8], and SMRL [9]. Incompatibility between the rPET and polyolefin leads to gross phase separation and poor mechanical properties of the blend [10]. For this reason, compatibilizers such as maleic anhydride polyethylene (MAPE) and maleic anhydride polypropylene (MAPP) are used to improve the compatibility between rPET and polyolefin $[11,12]$.

Some of the mechanical properties such as tensile strength and elastic modulus and thermal properties of rPET are reduced after physical recycling. Therefore, adding nanoparticles into the blend of rPET and polyolefin can improve the declined properties. Bizarria et al. [13] added montmorillonite (MMT) into rPET and observed that tensile strength and modulus were improved. Meri et al. [14] increased tensile strength and elastic modulus of rPET and reduced the creep by introducing the MMT into rPET. Rosnan et al. [15] reported that introducing MMT into the blend of rPET/HDPE improves the tensile strength, strain at break, and thermal stability. Yesil [16] found that carbon nanotube (CNT) improves dispersion of ethylene-ethyl acrylate-maleic anhydride (E-EA-MAH) in the blend of 
rPET/poly(ethylene naphthalate), and improves tensile strength, elastic modulus, and electrical properties. Chen et al. [17] reported that MMT increases the stiffness of recycled HDPE/PET nanocomposites.

Alumina nanoparticles as an effective filler in the polymer matrix can improve the mechanical and thermal properties of polymer matrixes. Bhimaraj et al. [18] reduced wear rate and friction coefficient of PET by adding alumina nanoparticles. Sezavar et al. [19] improved tensile properties and changed fracture mechanism of poly(methyl methacrylate) (PMMA) by introducing nano-sized alumina. Mallakpour et al. [20] increased the thermal stability temperature of poly(vinyl pyrrolidone) by adding modified alumina nanoparticles. Modification leads to good dispersion of nanoparticles into the matrix.

In the present study, HDPE/rPET/MAPE/alumina nanocomposites were prepared by melt mixing in a co-rotating screw extruder. Different weight percentages of nanoparticles $(0,1,3$, and 5$)$ were added into HDPE/rPET/MAPE matrix. Then, the effect of these nanoparticles on thermal properties and mechanical properties, including the tensile strength, elastic modulus, flexural strength, and impact energy, was investigated.

\section{Experimental}

\section{Materials}

A commercial grade of HDPE (HD-52518) with a density of $0.952 \mathrm{~g} / \mathrm{cm}^{3}$ and MFR of $18 \mathrm{~g} / 10 \mathrm{~min}\left(180^{\circ} \mathrm{C}, 2.16 \mathrm{~kg}\right)$ was prepared from Jam Petrochemical Company (Iran). Maleic Anhydride Polyethylene (MAPE) grade of 1040 was purchased from the Karangin Company, Iran. Because of the high melting temperature of $\mathrm{rPET}\left(252^{\circ} \mathrm{C}\right)$, Irganox 1010 thermal stabilizer (BASF Chemical Company, Germany) in the content of $0.06 \mathrm{wt} \%$ was used to prevent thermal degradation of HDPE. rPET was prepared from the waste bottles collected from Isfahan wastes. Alumina nanoparticles (alpha type) with an average diameter of $80 \mathrm{~nm}$ and $99 \%$ purity manufactured by US-NANO company (USA) were prepared. Transmission electron microscope (TEM) image of alumina nanoparticles is shown in Fig. 1.

\section{Tests}

To evaluate the effect of alumina nanoparticles on mechanical properties of HDPE/rPET, the tensile, flexural, and impact energy tests were done. The tensile and flexural tests were performed on HOUNSFIELD-H25KS machine with the speed of $3 \mathrm{~mm} / \mathrm{min}$ in room temperature according to ASTM D638 and ASTM D790, respectively. Charpy impact test was done on notched specimen based on ASTM D6110 A. To perform thermal analysis and to observe the morphology of specimens,



Fig. 1 TEM image of alumina nanoparticles

Table 1 Composition of the samples

\begin{tabular}{llllll}
\hline Sample & HDPE (wt\%) & rPET (wt\%) & $\begin{array}{l}\text { MAPE } \\
\text { (wt\%) }\end{array}$ & $\begin{array}{l}\text { Irgonax } \\
\text { (wt\%) }\end{array}$ & $\begin{array}{l}\text { Alu- } \\
\text { mina } \\
\text { (phr) }\end{array}$ \\
\hline S0 & 25 & 70 & 5 & 0.06 & 0 \\
S1 & 25 & 70 & 5 & 0.06 & 1 \\
S3 & 25 & 70 & 5 & 0.06 & 3 \\
S5 & 25 & 70 & 5 & 0.06 & 5 \\
\hline
\end{tabular}

differential scanning calorimetry (DSC) model of LABSYS1600 and scanning electron microscopy (SEM) model of VEGAIILMU were used, respectively.

\section{Sample preparation}

At first, waste rPET bottles were ground off, separated, and washed. Before compounding, HDPE, rPET, and MAPE were dried at $80{ }^{\circ} \mathrm{C}$ for $24 \mathrm{~h}$. Compounding of HDP/rPET/MAPE/ alumina nanocomposites with various contents (Table 1) was performed in a co-rotating screw extruder ZSK 25 with screw diameter and $L / D$ of $25 \mathrm{~mm}$ and 40 , respectively, within 245-265 ${ }^{\circ} \mathrm{C}$ temperature range. To prepare the test samples, the prepared granules were injected by the injection-molding machine at the temperature of $260^{\circ} \mathrm{C}$, and the speed of $54 \mathrm{rpm}$.

\section{Results and discussion}

\section{Morphology}

To determine how the alumina nanoparticles are dispersed in the polymer matrix, scanning electron microscopy (SEM) 
images from the fracture surface of the test specimens were taken. In general, most studies on the structure and distribution of nanoparticles in polymer matrices show that nanoparticles with generally low percentages usually show good dispersion. However, the presence of high weight percentages of nanoparticles in polymer matrices increases the chances of agglomerates.

The SEM images taken from the fracture surface of the sample containing 1 and $5 \mathrm{wt} \%$ of alumina nanoparticles are shown in Figs. 2 and 3, respectively. As shown in Fig. 2, a sample containing $1 \mathrm{wt} \%$ of alumina nanoparticles shows a good dispersion. In Fig. 2, the arrows represent nanoparticles. While in the sample contains $5 \mathrm{wt} \%$ of alumina nanoparticles (Fig. 3), the nanoparticles are stacked together and agglomerated. These agglomerates lead to poor mechanical properties. Agglomerate parts have been shown by arrows in Fig. 3.

\section{Mechanical properties}

\section{Tensile test}

Stress-strain curves of HDPE/rPET/MAPE reinforced with various content of alumina nanoparticles $(1,3$, and $5 \mathrm{wt} \%$ ) are shown in Fig. 4. Table 2 shows the results of tensile tests. According to presented results in Table 2, tensile strength increased by introducing the alumina nanoparticles. The tensile strength increased significantly from 22.6 MPa for the base sample (S0) up to $33.5 \mathrm{MPa}$ for the sample with $3 \mathrm{wt} \%$ of nano-alumina (S3). This increase shows that alumina nanoparticles are effective filler in the reinforcement of HDPE/rPET/MAPE matrix. Some researchers reported that the tensile strength of the samples in the presence of nanoparticles cannot be more than neat polymer, because the nanoparticles

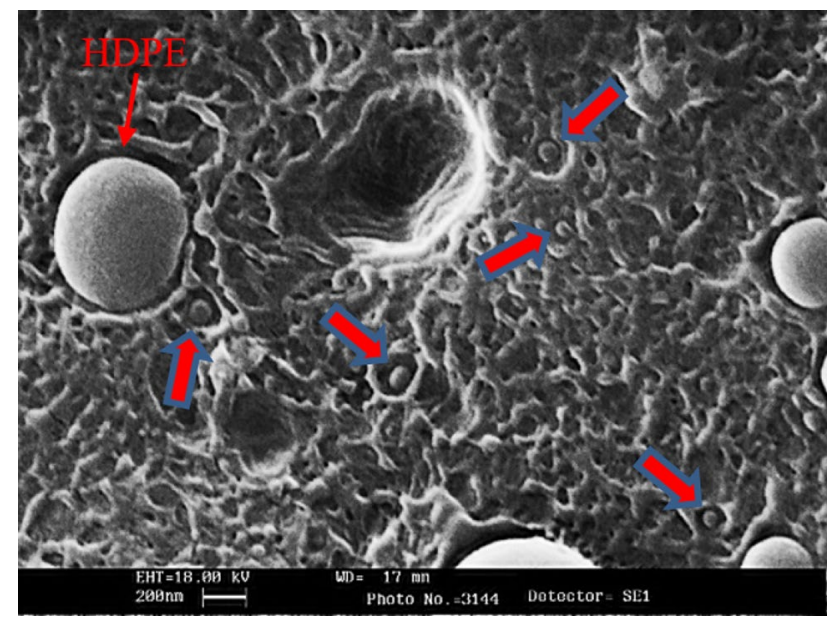

Fig. 2 Sample with $1 \mathrm{wt} \%$ alumina nanoparticles. Arrows show nanoparticles

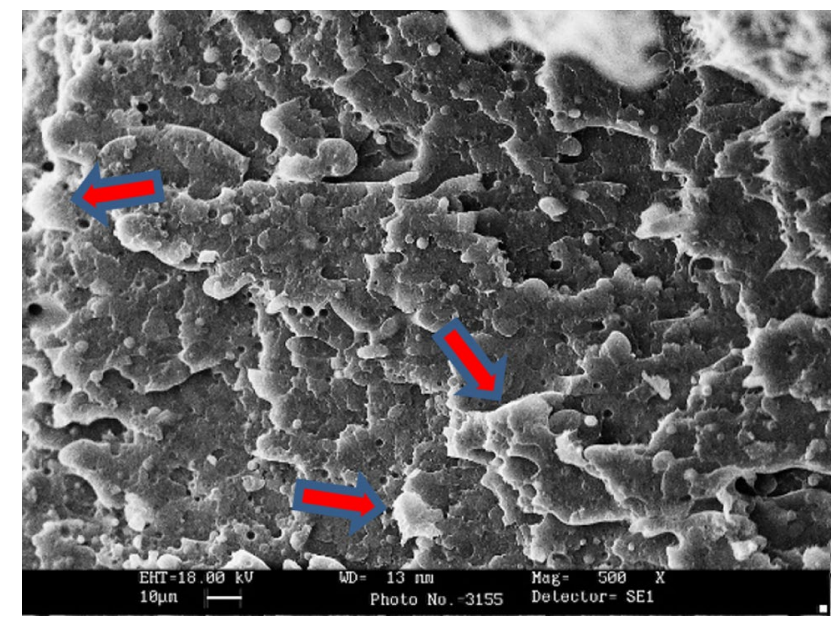

Fig. 3 Sample with $5 \mathrm{wt} \%$ alumina nanoparticles. Arrows indicate nanoparticle agglomerates

cannot support any fraction of the external load [21]. The increase of tensile strength in this study shows that nanoparticles have formed a good interface with the polymer matrix, so that nanoparticles have been able to support the fraction of external load. This can be due to the use of MAPE compatibilizer. Due to the presence of a polar head and a non-polar head, MAPE compatibilizer has been able to create an interface or bond between the matrix and the nanoparticles. Zhao et al. [22] reported that alumina nanoparticles increase mechanical properties of polymer/ alumina nanocomposite by activating the toughening mechanisms including crack deflection, debonding, and plastic deformation of the debonded matrix.

The elastic modulus of HDPE/rPET/alumina nanocomposites is shown in Table 2. As can be seen, adding alumina nanoparticles into the polymer matrix increases the tensile modulus and then decreases. The reason for this increase can be the good dispersion of nanoparticles with 1 and $3 \mathrm{wt} \%$, followed by a good adhesion between the nanoparticles and the polymer matrix (due to the use of MAP), while the addition of more than $3 \mathrm{wt} \%$ of alumina nanoparticles to $5 \mathrm{wt} \%$ leads to a reduction in tensile modulus due to the agglomeration of nanoparticles. The excess content of nanoparticles in some samples acts as a defect and ultimately reduces the elastic modulus of the compounds. This result is consistent with the findings of Altan et al. [23] that have reported an increase in the elastic modulus in the case of the addition of titanium oxide nanoparticles into the polypropylene polymer matrix.

\section{Impact energy test}

Figure 5 shows the impact strength of HDPE/rPET versus different amounts of nanoparticles. As can be seen, by 
Fig. 4 Stress-strain curve of the samples

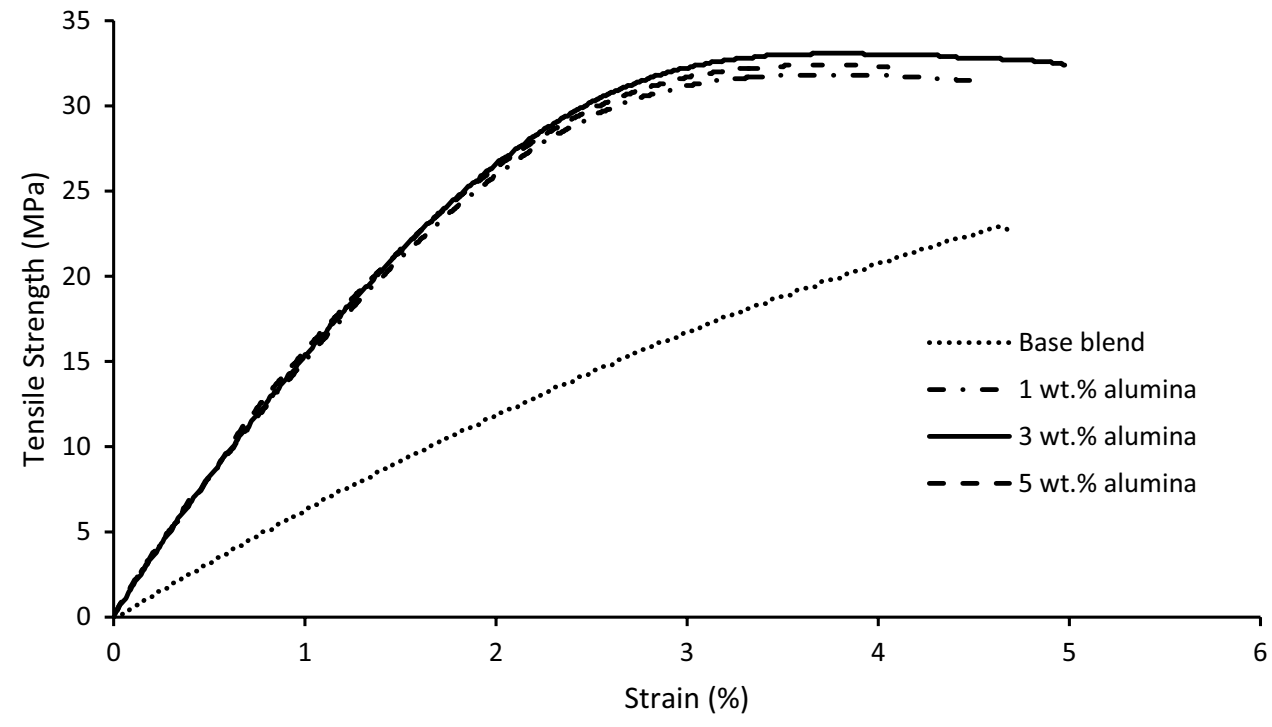

Table 2 Tensile properties of the samples

\begin{tabular}{llll}
\hline Sample & $\begin{array}{l}\text { Tensile strength } \\
(\mathrm{MPa})\end{array}$ & $\begin{array}{l}\text { Elastic modulus } \\
(\mathrm{MPa})\end{array}$ & $\begin{array}{l}\text { Elongation } \\
\text { at break }(\%)\end{array}$ \\
\hline S0 & $22.6 \pm 2.5$ & $1470 \pm 35$ & $4.68 \pm 0.14$ \\
S1 & $31.5 \pm 1.6$ & $1542 \pm 44$ & $4.48 \pm 0.12$ \\
S3 & $33.5 \pm 2.3$ & $1574 \pm 45$ & $4.97 \pm 0.21$ \\
S5 & $32 \pm 2.6$ & $1556 \pm 51$ & $4.14 \pm 0.16$ \\
\hline
\end{tabular}

adding alumina nanoparticles into the polymer matrix, the significant changes in impact strength are obtained, such that the strength of the impact increases first and then decreases.
The impact energy of $3.57 \mathrm{~kJ} / \mathrm{m}^{2}$ for the base sample (S0) increased up to $6.9 \mathrm{~kJ} / \mathrm{m}^{2}$ for the sample of $\mathrm{S} 3$ and then decreased to $4.52 \mathrm{~kJ} / \mathrm{m}^{2}$ for the sample of $\mathrm{S} 5$.

The increase of impact strength is due to good dispersion of nanoparticles in the sample containing $3 \mathrm{wt} \%$ of alumina nanoparticles in the polymer matrix. It seems that the nanoparticles in polymer matrix act as a cavitation agent. Since the production of the cavity is associated with energy consumption, the impact energy of the samples rises. Of course, this mechanism is highly dependent on the geometry of particles and has been reported by researchers for spherical particles such as calcium carbonate [24, 25]. On the other hand, an increase in the content of nanoparticles up to $5 \mathrm{wt} \%$
Fig. 5 Impact energy changes versus different alumina nanoparticles' contents $0,1,3$, and $5 \mathrm{wt} \%$

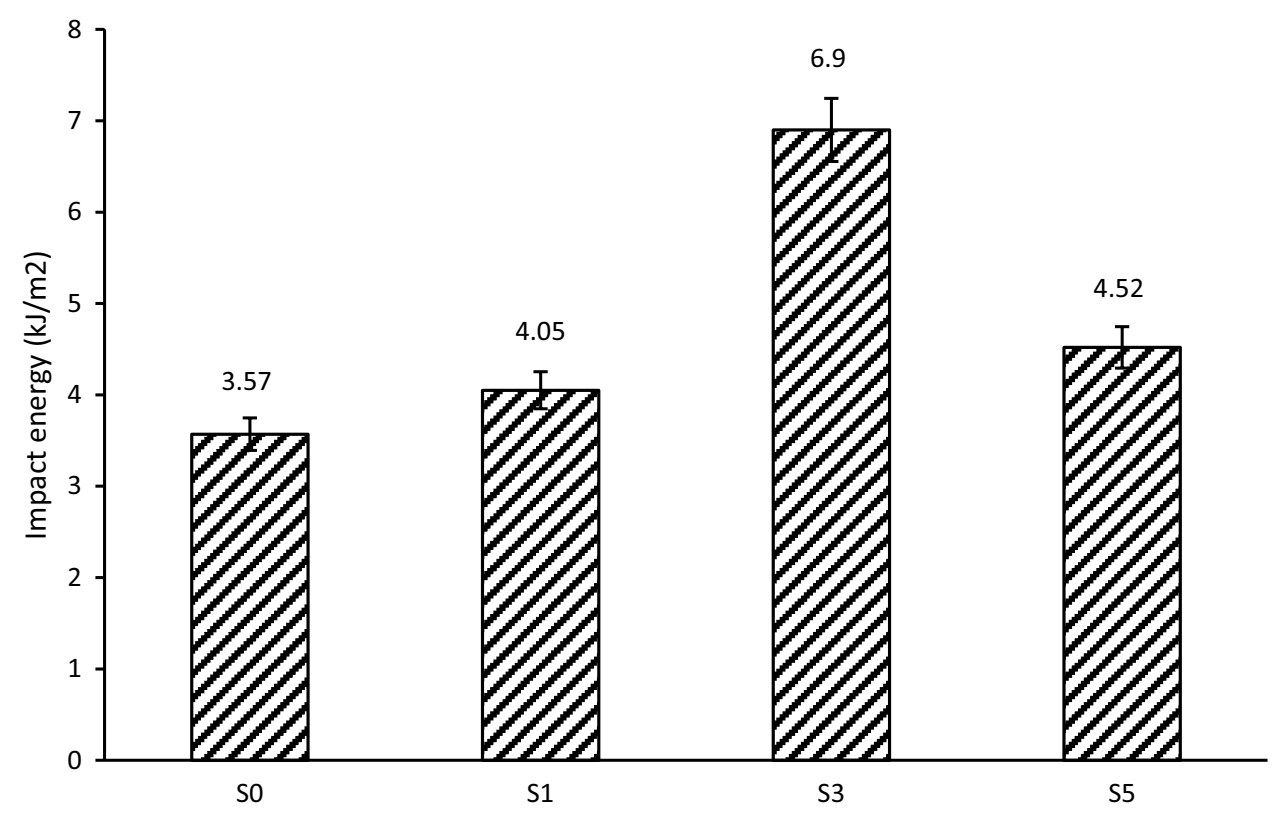


has reduced the impact strength due to the agglomeration of nanoparticles. The impact strength of the sample in the presence of $5 \mathrm{wt} \%$ of nanoparticles, however, is still greater than the base sample (S0).

\section{Flexural test}

Figure 6 shows the flexural strength of HDPE/rPET with different amounts of alumina nanoparticles. As can be seen, the flexural strength of the samples is generally increased by adding alumina nanoparticles to the polymer matrix. The maximum flexural strength $(44.86 \mathrm{MPa})$ is observed for the sample containing $3 \mathrm{wt} \%$ of alumina nanoparticles. By adding the nanoparticles up to $5 \mathrm{wt} \%$, the flexural strength reduces. This can be due to the agglomeration of nanoparticles in the high concentration of nanoparticles.

Fig. 6 Flexural strength of the samples versus different alumina nanoparticles' contents $0,1,3$, and $5 \mathrm{wt} \%$

Fig. 7 DSC endothermic curve for HDPE, rPET, rPET/HDPE/ MAPE (S0), and rPET/HDPE/ MAPE $/ 3 \mathrm{wt} \%$ alumina nanoparticles (S3)

\section{Thermal properties}

To investigate the thermal behavior of rPET, HDPE, base sample (S0), and the sample containing $3 \mathrm{wt} \%$ of alumina nanoparticles (S3), DSC test was used done. Figure 7 shows the DSC endothermic curve for HDPE, rPET, rPET/ HDPE/MAPE, and RPET/HDPE/MAPE/3 wt $\%$ of alumina nanoparticles. The results of the DSC test are summarized in Table 3. As shown in Fig. 7, the rPET exhibits an endothermic peak at a temperature of $252.62{ }^{\circ} \mathrm{C}$, which indicates its melting temperature. In HDPE, the peak of melting has appeared at $127{ }^{\circ} \mathrm{C}$. In the blend samples, two endothermic peaks are seen in both samples of $\mathrm{S} 0$ and S3. This indicates that rPET and HDPE are not compatible with each other. Therefore, two separate melting temperatures can be seen. The existence of two distinct peaks expresses two completely different crystallization
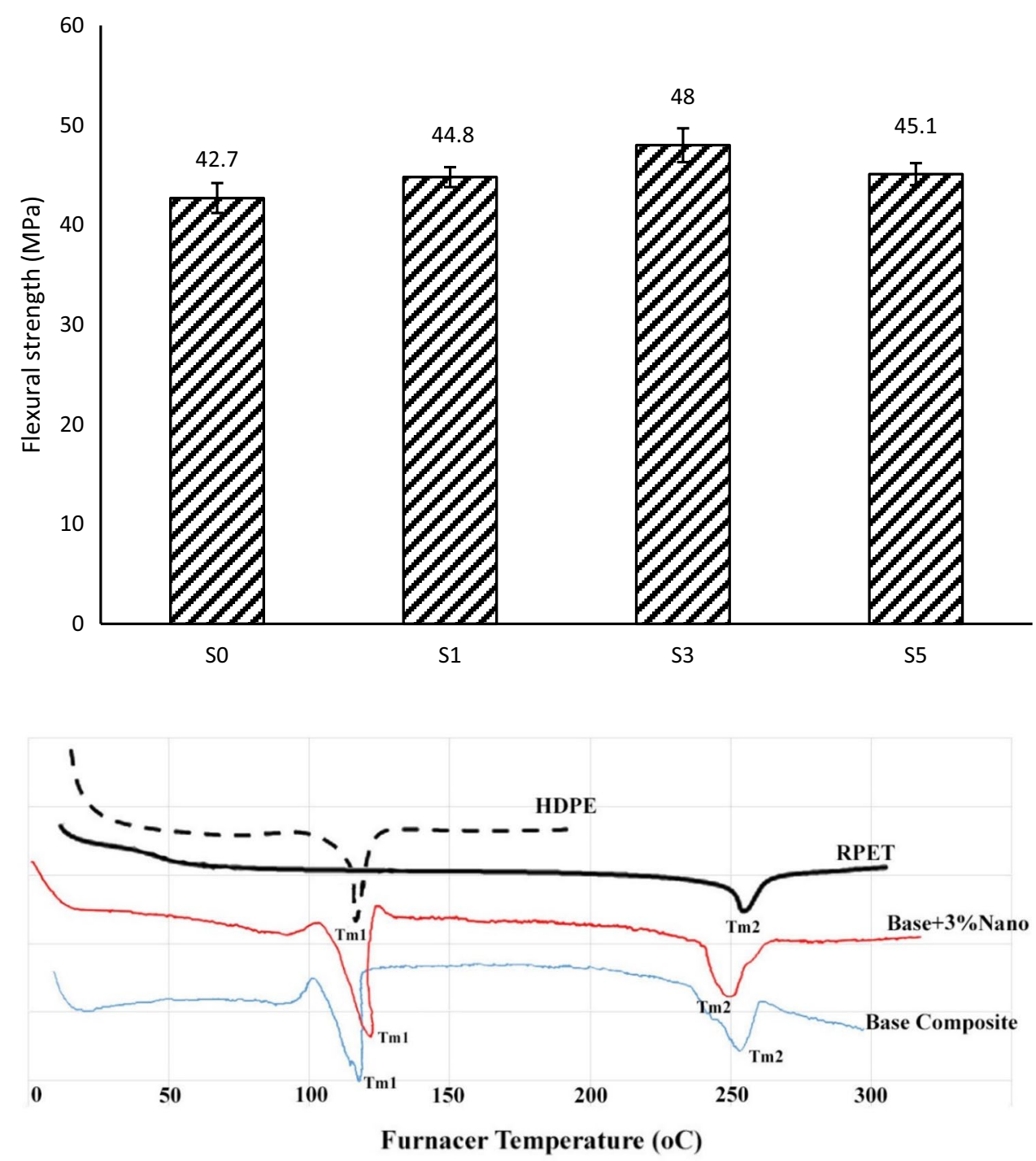
Table 3 Thermal analysis of rPET, HDPE, rPET/HDPE/MAPE, and rPET/HDPE/MAPE/3 wt\% alumina nanoparticles

\begin{tabular}{lllll}
\hline Characteristic & HDPE & rPET & $\begin{array}{l}\text { rPET/ } \\
\text { HDPE/ } \\
\text { MAPE }\end{array}$ & $\begin{array}{l}\text { rPET/HDPE/ } \\
\text { MAPE/3 wt\% alumina } \\
\text { nanoparticles }\end{array}$ \\
\hline$T_{\mathrm{m} 1}\left({ }^{\circ} \mathrm{C}\right)$ & 127 & - & 127.8 & 128.7 \\
$T_{\mathrm{m} 2}\left({ }^{\circ} \mathrm{C}\right)$ & - & 252.62 & 252.1 & 249.7 \\
$T_{\mathrm{m} 2}-T_{\mathrm{m} 1}\left({ }^{\circ} \mathrm{C}\right)$ & - & - & 124.3 & 120 \\
$\Delta H_{\mathrm{m} 1}(\mathrm{~J} / \mathrm{g})$ & 160 & - & 24.33 & 21.88 \\
$\Delta H_{\mathrm{m} 2}(\mathrm{~J} / \mathrm{g})$ & - & 29.2 & 28.81 & 21.71 \\
$X_{\mathrm{m} 1}(\%)$ & 54.6 & - & 27.67 & 33.1 \\
$X_{\mathrm{m} 2}(\%)$ & - & 20.85 & 22.32 & 22.37 \\
\hline
\end{tabular}

structures, resulting in different melting points $\left(T_{\mathrm{m} 1}\right.$ and $T_{\mathrm{m} 2}$ ) for these specimens.

However, with more precision in Fig. 7 and the results presented in Table 3, it can be seen that by blending the rPET and HDPE, the melting temperature of the HDPE phase is shifted to higher value a little. This is due to the MAPE compatibilizer. It can be seen from this table that by introducing the MAPE to the HDPE/rPET blend, the melting temperature of HDPE is shifted from $127^{\circ} \mathrm{C}$ to $127.8^{\circ} \mathrm{C}$. The difference in melting temperature between rPET and HDPE was $125.62{ }^{\circ} \mathrm{C}$, so using MAPE compatibilizer, the difference has reached $124.3^{\circ} \mathrm{C}$.

By adding $3 \mathrm{wt} \%$ of alumina nanoparticles to the base sample, it is observed that the melting temperature of HDPE shifted from 127 to $128.7^{\circ} \mathrm{C}$ and the melting point of rPET from 252.62 to $249.7{ }^{\circ} \mathrm{C}$. As shown in Table 3, the difference in melting temperatures of rPET and HDPE in the rPET/HDPE/MAPE blend was $124.3^{\circ} \mathrm{C}$; however, by adding the nanoparticles to the blend, the difference in temperature reached to $120^{\circ} \mathrm{C}$, which shows improvement in compatibility of rPET and HDPE. To determine the crystallization degree, the following equation was used:

$X_{c}=\frac{\Delta H_{\mathrm{m}}}{w \times \Delta H_{\mathrm{m}}^{0}}$,

where $\Delta H_{\mathrm{m}}(\mathrm{J} / \mathrm{g})$ is the sample enthalpy, $\Delta H_{\mathrm{m}}^{0}(\mathrm{~J} / \mathrm{g})$ is the enthalpy of $100 \%$ crystalline sample, and $w$ is the weight percentage of filler or polymer in the blend.

Based on the data in Table 3, the crystallization degree of HDPE in nanocomposite containing $3 \mathrm{wt} \%$ of alumina nanoparticles was $33.1 \%$, which showed an improvement of $19.6 \%$ compared to the crystallization degree of HDPE in HDPE/rPET/MAPE (27.67\%). This reflects the improvement of nucleation in the blend by adding the alumina nanoparticles, which has increased the crystallization degree of HDPE and has brought two melting temperature peaks to close together. By calculating the crystallization degree of rPET in the presence of alumina nanoparticles, it can be seen that the crystallization degree of rPET increased slightly (about $0.2 \%$ ).

\section{Conclusion}

In this study, the effect of alumina nanoparticles on the mechanical (tensile, flexural, and impact energy) and thermal properties of HDPE/rPET/MAPE blend was investigated. The results showed:

1. The addition of alumina nanoparticles up to $3 \mathrm{wt} \%$ into HDPE/rPET/MAPE matrix results in an increase of 48 , 12.5 and $7 \%$ in the tensile strength, flexural strength, and elastic modulus, respectively.

2. The presence of nanoparticles up to $3 \mathrm{wt} \%$ significantly increases the impact strength of HDPE/rPET/MAPE (about 95\%).

3. The results of the thermal test of DSC indicated that by adding the alumina nanoparticles, melting point temperature of HDPE and rPET is close together, and the crystallization degree of HDPE increases.

Open Access This article is distributed under the terms of the Creative Commons Attribution 4.0 International License (http://creativeco mmons.org/licenses/by/4.0/), which permits unrestricted use, distribution, and reproduction in any medium, provided you give appropriate credit to the original author(s) and the source, provide a link to the Creative Commons license, and indicate if changes were made.

\section{References}

1. Awaja, F., Pavel, D.: Recycling of PET. Eur. Polymer J. 41, 14531477 (2005)

2. Welle, F.: Twenty years of PET bottle to bottle recycling-an overview. Resour. Conserv. Recycl. 55, 865-875 (2011)

3. Ge, Z., Huang, D., Sun, R., et al.: Properties of plastic mortar made with recycled polyethylene terephthalate. Constr. Build. Mater. 73, 682-687 (2014)

4. López, MdMC, Pernas, A.I.A., López, M.J.A., et al.: Assessing changes on poly (ethylene terephthalate) properties after recycling: mechanical recycling in laboratory versus postconsumer recycled material. Mater. Chem. Phys. 147, 884-894 (2014)

5. Krehula, L.K., Siročić, A.P., Dukić, M., et al.: Cleaning efficiency of poly (ethylene terephthalate) washing procedure in recycling process. J. Elastom. Plast. 45, 429-444 (2013)

6. Navarro, R., Ferrandiz, S., Lopez, J., et al.: The influence of polyethylene in the mechanical recycling of polyethylene terephtalate. J. Mater. Process. Technol. 195, 110-116 (2008)

7. Meran, C., Ozturk, O., Yuksel, M.: Examination of the possibility of recycling and utilizing recycled polyethylene and polypropylene. Mater. Des. 29, 701-705 (2008)

8. Khatibi, M.A., Arefazar, A., Esfandeh, M.: Microstructure and properties of PET/EPDM, EPDM-g-MA/organoclay ternary hybrid nanocomposites: effect of blending sequence. e-Polymers 8, 164 (2008) 
9. Nabil, H., Ismail, H., Azura, A.: Recycled polyethylene terephthalate filled natural rubber compounds: effects of filler loading and types of matrix. J. Elastom. Plast. 43, 429-449 (2011)

10. Dimitrova, T., La Mantia, F., Pilati, F., et al.: On the compatibilization of PET/HDPE blends through a new class of copolyesters. Polymer 41, 4817-4824 (2000)

11. Taghavi, S.K., Shahrajabian, H., Hosseini, H.M.: Detailed comparison of compatibilizers MAPE and SEBS-g-MA on the mechanical/thermal properties, and morphology in ternary blend of recycled PET/HDPE/MAPE and recycled PET/HDPE/SEBSg-MA. J. Elastom. Plast. 50, 13-35 (2018)

12. Inoya, H., Wei Leong, Y., Klinklai, W., et al.: Compatibilization of recycled poly (ethylene terephthalate) and polypropylene blends: effect of compatibilization on blend toughness, dispersion of minor phase, and thermal stability. J. Appl. Polym. Sci. 124, 5260-5269 (2012)

13. Bizarria, M., Giraldi, ALdM, de Carvalho, C.M., et al.: Morphology and thermomechanical properties of recycled PET-organoclay nanocomposites. J. Appl. Polym. Sci. 104, 1839-1844 (2007)

14. Meri, R.M., Zicans, J., Maksimovs, R., et al.: Elasticity and longterm behavior of recycled polyethylene terephthalate (rPET)/ montmorillonite (MMT) composites. Compos. Struct. 111, 453458 (2014)

15. Rosnan, R.M., Arsad, A.: Effect of MMT concentrations as reinforcement on the properties of recycled PET/HDPE nanocomposites. J. Polym. Eng. 33, 615-623 (2013)

16. Yesil, S.: Effect of carbon nanotube reinforcement on the properties of the recycled poly (ethylene terephthalate)/poly (ethylene naphthalate)(r-PET/PEN) blends containing functional elastomers. Mater. Des. 52, 693-705 (2013)

17. Chen, R.S., Ahmad, S., Gan, S., et al.: Effects of compatibilizer, compounding method, extrusion parameters, and nanofiller loading in clay-reinforced recycled HDPE/PET nanocomposites. J. Appl. Polym. Sci. 132, 42287 (2015)

18. Bhimaraj, P., Burris, D.L., Action, J., et al.: Effect of matrix morphology on the wear and friction behavior of alumina nanoparticle/poly (ethylene) terephthalate composites. Wear 258, 1437-1443 (2005)

19. Sezavar, A., Zebarjad, S.M., Sajjadi, S.A.: A study on the effect of Nano Alumina Particles on Fracture Behavior of PMMA. Technologies 3, 94-102 (2015)

20. Mallakpour, S., Sadeghzadeh, R.: Surface functionalization of $\mathrm{Al}_{2} \mathrm{O}_{3}$ nanoparticles with biocompatible modifiers, preparation and characterization of poly (vinyl pyrrolidone)/modified $\mathrm{Al}_{2} \mathrm{O}_{3}$ nanocomposites. Polym Plast Technol Eng 56, 1866-1873 (2017)

21. Wacharawichanant, S., Thongyai, S., Siripattanasak, T., et al.: Effect of mixing conditions and particle sizes of titanium dioxide on mechanical and morphological properties of polypropylene/ titanium dioxide composites, Iran. Polym. J. 18, 607-616 (2009)

22. Zhao, S., Schadler, L.S., Duncan, R., et al.: Mechanisms leading to improved mechanical performance in nanoscale alumina filled epoxy. Compos. Sci. Technol. 68, 2965-2975 (2008)

23. Altan, M., Yildirim, H.: Mechanical and morphological properties of polypropylene and high density polyethylene matrix composites reinforced with surface modified nano sized $\mathrm{TiO}_{2}$ particles. World Acad. Sci. Eng. Technol. 4, 252-257 (2010)

24. Ghalia, M.A., Hassan, A., Yussuf, A.: Mechanical and thermal properties of calcium carbonate-filled PP/LLDPE composite. J. Appl. Polym. Sci. 121, 2413-2421 (2011)

25. Gonzalez, J., Albano, C., Ichazo, M., et al.: Effects of coupling agents on mechanical and morphological behavior of the PP/ HDPE blend with two different $\mathrm{CaCO}_{3}$. Eur. Polym. J. 38, 24652475 (2002)

Publisher's Note Springer Nature remains neutral with regard to jurisdictional claims in published maps and institutional affiliations. 